\title{
Efficacy of the combination of herbal extracts and a silicone derivative in the treatment of hypertrophic scar formation after burn injury
}

\author{
P. Muangman ${ }^{1 \star}$, P. Aramwit ${ }^{2}$, S. Palapinyo ${ }^{2}$, S. Opasanon ${ }^{3}$ and A. Chuangsuwanich ${ }^{3}$ \\ ${ }^{1}$ Trauma Division, Department of Surgery, Siriraj Hospital, Mahidol University, Bangkok, Thailand. \\ ${ }^{2}$ Department of Pharmacy Practice, Faculty of Pharmaceutical Sciences, Chulalongkorn University, Bangkok, Thailand. \\ ${ }^{3}$ Division of Plastic and Reconstructive Surgery, Department of Surgery, Siriraj Hospital, Mahidol University, \\ Bangkok, Thailand.
}

Accepted 7 April, 2011

\begin{abstract}
The development of hypertrophic scars is an unsolved problem in the process of wound healing. The objective of this research was to study the efficacy of the combination of herbal extracts and a silicone derivative in a gel preparation (Cybele ${ }^{\circledR}$ Scagel) on the treatment of deep second degree burns after complete epithelialization. Sixty-three patients were enrolled in this study. One wound area larger than $10 \times 10 \mathrm{~cm}$ was selected from each patient to receive treatment with Cybele ${ }^{\circledR}$ Scagel. Patients were observed for pigmentation, pliability, pain and itching for $0,2,4,8,12,16,20$ and 24 weeks after treatment. Their data and wound characteristics were collected during each visit using the Vancouver scar scale. After 24 weeks, all scales (pigmentation, pliability, pain and itching) were significantly lower in the sites treated with Cybele ${ }^{\circledR}$ Scagel compared with the previous time points $(p<0.05)$. However, vascularity and height scale were not significantly different $(p>0.05)$. One patient was excluded at week 2 because of moderate itching at the wound site, which could have interfered with the evaluation. The application of Cybele ${ }^{\circledR}$ Scagel might have some beneficial effects for prevention of hypertrophic scar formation after partial thickness burn injuries.
\end{abstract}

Key words: Herbal extracts, burn, hypertrophic scar.

\section{INTRODUCTION}

Hypertrophic scarring following surgical procedures, traumatic accidents and especially burns is of great concern for patients and a challenging problem for clinicians. It can cause significant functional and cosmetic impairment as well as symptoms of pruritis and pain, which are all responsible for a decrease in quality of life (Beldon, 2000; Bloemen et al., 2009; Bock et al., 2006). Hypertrophic scars result from the general failure of the normal wound healing processes and represent an exaggerated proliferative response to wound healing that stays within the boundaries of the original wound.

${ }^{*}$ Corresponding author. E-mail: sipmm@mahidol.ac.th. Tel: +6602-419-7727. Fax: +66-02-419-7730.
Collagen in hypertrophic scars is found to be in a disorganized, whorl-like arrangement rather than in the normal parallel orientation manner. Therefore, hypertrophic scars are indurate, elevated, poorly extensible and also characterized by hypervascularity, thereby providing their erythematous appearances (Alster and West, 1997; Scott et al., 2007; Van Loey et al., 2008).

The development of hypertrophic scars is an unsolved problem in the process of wound healing. For this reason, a yet undiscovered successful treatment is needed to prevent excessive scar formation. Burn scar management aims to prevent scars from interfering with functions and to make them cosmetically acceptable. This goal should be achieved as comfortably, quickly and inexpensively as possible. Patients prone to healing problems should receive preventive treatment. These preventions usually include topical medical application, 
cryotherapy, the use of silicone gel sheets, the injection of steroids, radiotherapy and an early surgical procedure for wound closure. Recent reports have introduced the use of extracts from natural sources such as plant extracts in an attempt to correct these problems (Muangman et al., 2006; Stella et al., 2008; Zurada et al., 2006).

Previous research has reported that some herbal extracts have demonstrated beneficial effects on scar treatment (Bombaro et al., 2003; Hosnuter et al., 2007; Lawrence, 1967; Widgerow et al., 2000). Quercetin, a bioflavonoid from Allium cepa, has shown antiproliferative effects on both normal and malignant cells and also exhibited antihistamine release effects. These properties could theoretically prove beneficial in reversing the inflammatory and proliferative responses (Bombaro et al., 2003; Widgerow et al., 2000). Willital and Heine (1994) reported using onion extracts to treat fresh scars after thoracic surgery in 45 cases of children and adolescents. They treated these cases starting from day 26 and following up for one year. They found that $90 \%$ of patients who received this treatment showed good to very good outcomes.

Allantoin has shown both cell proliferant (removal of necrotic tissue) and epithelialization (skin growth) properties and thereby hastens the growth of new healthy tissue over wounds and sores. Allantoin is also a counterirritant that helps alleviate skin irritation. Centella asiatica Linn, has been shown to promote fibroblast proliferation and collagen synthesis (Hosnuter et al., 2007; Lawrence, 1967). Asiaticoside is extracted from gotu kola leaves that are effective in the control of the production of collagen type 1. Owing to substances in gotu kola leaves, there is a decrease in inflammatory reaction and the production of myofibroblasts is reduced. Thus, this substance decreases the chance of hypertrophic scar formation. Using a rabbit ear model, Ju-Lin et al. (2009) reported that asiaticoside could alleviate scarring by decreasing transform growth factor beta-1 expression and enhancing the expression of inhibitory Smad 7, resulting in an antiscarring effect. Tamarind extract relates to its anti-inflammatory activity and may remove death cells and necrotic tissues (Havinga et al., 2010). Aloe vera is another well-known substance that is believed to enhance wound healing. Chithra et al. (1998) reported that aloe vera causes changes in the production of collagen around the wound and Vazquez et al. (1996) found aloe vera extract to be an antagonist to the inflammatory process. It interferes with the action of cyclooxygenase, which is the precursor to the production of arachidonic acid. Aloe vera acts as a TxA2 inhibitor so it has an anti-inflammatory effect (Heggers et al., 1996). It also has moisture that may relieve pain and itching. Aloe vera seems to expedite wound contraction and neutralize the wound retardant effect (Heggers et al., 1996). It also increases collagen activity, which is enhanced by a lectin, consequently improving the collagen matrix and enhancing the breaking strength. The extract, kazinol F, from the bark and root of paper mulberry inhibits the synthesis of the tyrosinase enzyme that is responsible for the creation of melanin and skin pigmentation (Baek et al., 2009). It is also useful for the prevention of hyperpigmentation in wound healing and scar prevention therapy (Sasaki et al., 1972; Willital and Heine, 1994). It has been reported that kazinol $\mathrm{F}$ is more potent than kojic acid, ascorbic acid and hydroquinone (Baek et al., 2009). Silanol is an end product of a biosubstance called nano hydroxyprolisilane $\mathrm{C}$.

This is an analog of silicone and hydroxyproline. Reports have shown that silicone benefits the process of wound healing and prevents hypertrophic scarring (Sasaki et al., 1972; Spencer, 2010; Van der Wal et al., 2010) by softening the texture of wounds and brightening their color (Gold et al., 2001). Most researchers believe that this occurs because of the polarization of silicone (Van der Wal et al., 2010). Silicone helps realign the collagen fiber during the wound healing process and maintains a moist environment; hence, it contributes to the natural colorization of scars (Tandara and Mustoe, 2008). Because hypertrophic scarring is complicated and involves several factors, combination agents are necessary to control or improve the appearance of that defect. Herbal extracts combined with a silicone derivative might be helpful in the process of wound healing and could be beneficial for the prevention of scar formation.

Cybele ${ }^{\circledR}$ Scagel is a combination of herbal extracts and a silicone derivative in a gel preparation mainly composed of $12 \%$ A. cepa (onion extract), $1 \%$ allantoin, asiaticoside (extracted from the gotu kola leaf), aloe vera (Aloe barbadensis) extract, kazinol $\mathrm{F}$ (paper mulberry extract), tamarind extract and nano hydroxyprolisilane C. It was developed for hypertrophic scar treatment. Previous study have been reported that the use of this topical agent can reduce pain and itching symptom after epithelialization of burn wound and may prevent hypertrophic scar formation after burn injury (Muangman et al., 2011). This study was designed to assess the potential benefits of Cybele ${ }^{\circledR}$ Scagel on the prevention of burn scars after partial thickness burn injury.

\section{METHODS}

The retrospective chart review without control group was performed on 63 partial thickness burn patients treated at the Siriraj Outpatient Burn Clinic, Department of Surgery, Siriraj Hospital during January 2008 to January 2010. This study was approved by the institutional review board of the hospital. Wounds were allowed to heal spontaneously with no skin graft.

One wound area with a diameter larger than $10 \times 10 \mathrm{~cm}$ was selected from each patient to receive the topical treatment of Cybele $^{\circledR}$ Scagel approximately three grams which was enough amount of gel to completely cover the wounds. The gel was applied twice daily to the second or partial thickness burn wounds on the respective locations after complete epithelialization healing.

One surgeon was assigned to evaluate the burn wounds throughout the study. Demographic data were recorded including 
Table 1. The Vancouver scar scale.

\begin{tabular}{|c|c|}
\hline Pigmentation & $0=$ normal, $1=$ hypopigmented $2=$ mixed $3=$ hyperpigmented \\
\hline Vascularity & $0=$ normal, $1=$ pink, $2=$ red, $3=$ purple \\
\hline Pliability & $\begin{array}{l}0=\text { normal, } 1=\text { supple } / \text { flexible, } 2=\text { yielding to pressure, } 3=\text { firm } / \text { inflexible } \\
4=\text { bandina/rope like }, 5=\text { contracture }\end{array}$ \\
\hline Height & $0=$ flat, $1=>2 \mathrm{~mm}, 2=2-5 \mathrm{~mm}, 3=>5 \mathrm{~mm}$ \\
\hline Pain & $0=$ none, $1=$ occasional, $2=$ require medication \\
\hline Itching & $0=$ none, $1=$ occasional, $2=$ require medication. \\
\hline
\end{tabular}

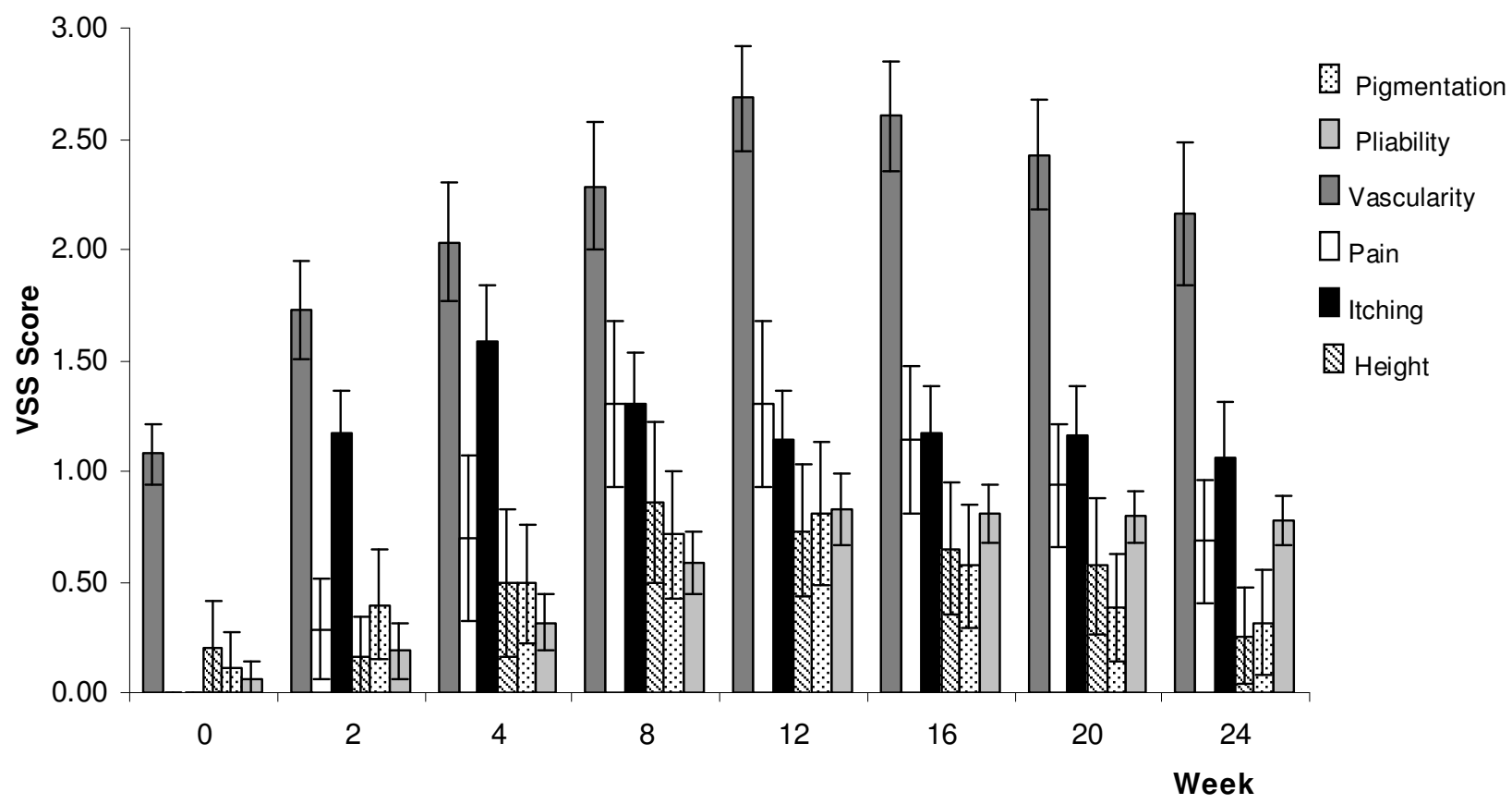

Figure 1. The results of wound pigmentation, pliability, vascularity, pain, itching and height after treatment with Cybele ${ }^{\circledR}$ Scagel.

age, sex, cause of injury and percentage of total body surface area burned. The Vancouver scar scale (VSS) (Baryza and Baryza, 1995; Bloemen et al., 2009; Rennekampff et al., 2006) which is composed of six parameters (pigmentation, vascularity, pliability, height, pain and itching), was used to assess wounds after epithelialization. The details of the VSS are shown in Table 1. A digital camera recorded serial changes in the wounds. The height of the wounds at each time of follow up was recorded as millimeters. The treatment and evaluation procedures were started after complete epithelialization healing at week 0 . Participants were followed up after 2, 4, 8, 12, 16, 20 and 24 weeks for observation. The highest time point score of each of six parameters (pigmentation, vascularity, pliability, height, pain and itching) were recorded and compared to the score at the end time of treatment (week 24). Two experienced burn surgeons were assigned to observe and rate the wounds using the VSS scale.

SPSS software version 17 was used for analysis of the results. Significant differences of scar score parameters between two time points previously described were detected by the $t$ test. A $p$ value < 0.05 was considered significant.

\section{RESULTS}

The mean age of the 63 participants was 35 years ( 2 to 68 years, 37 males). The burn wounds of 39 participants were caused by scalding, whereas for the others they were caused by flame. The mean percentage of total body surface area burned for each patient was $27 \%(95 \%$ $\mathrm{Cl}$ of 12 to $42 \%$ ).

The results of wound pigmentation, pliability, vascularity, pain, itching and height of each time point are shown in Figure 1, scored according to the VSS. At the beginning of injury, the VSS score for all parameters was low (less than one). Parameters of pigmentation, pliability, height itching were gradually increased until reach the highest point at week 12 . The parameters of vascularity and pain were highest at week 4 and 8 , respectively. Almost all scales for pigmentation, pliability, 
pain and itching at the end point of treatment (week 24) were significantly decreased in the sites applied with Cybele ${ }^{\circledR}$ Scagel compared with the previous highest time point score of pigmentation (week 12), pliability (week 12), pain (week 8), and itching (week 12), $(p=0.027$, $0.014,0.01,0.004$, respectively). Nevertheless, the vascularity (week 4 ), and height scale (week 12) values were not significantly decreased $(p=0.05$ and 0.06 , respectively). No side effects or allergies were found in any patients.

\section{DISCUSSION}

Many factors can contribute to scar formation including ethnicity (Rockwell et al., 1989), genetic influences (Brown and Bayat, 2009; Shih and Bayat, 2010), anatomical region affected, wound depth, injury type (Gangemi et al., 2008), the presence of infection and prolonged immune responses (Singer and McClain, 2002). Excessive scar formation is simply the end result of the healing process and can lead to serious functional and cosmetic problems (Sherris et al., 1995). Many studies have addressed these problems and many treatment methods have been used (Bock et al., 2006; Gauglitz et al., 2011). Patients prone to scar formation during wound healing should receive early preventive treatment (Berman et al., 2008).

The use of Cybele ${ }^{\circledR}$ Scagel was convenient, resulting in good compliance with the patients experiencing good recovery of the wound and body functions (for example, ease of movement of the limbs). Our results also indicated the benefit of herbal extract ingredients composed in Cybele ${ }^{\circledR}$ Scagel for preventing scar formation, similar to the results previously reported by others (Chithra et al., 1998; Gold et al., 2001; Hosnuter et al., 2007). Since inflammation has been recognized as an early participant in wound healing (Henry and Garner, 2003), vascularity and pain are normally found at an early stage, which was shown in our results. Itching, pigmentation and the enlargement of the wound as indicated by wound height usually occur in late stages of wound healing. Unfortunately, pigmentation and wound height occasionally result in permanent scarring. The recovery of skin pigmentation may be the effect of kazinol $F$ from the bark and root of paper mulberry which inhibits the synthesis of the tyrosinase enzyme that is responsible for the creation of melanin and skin pigmentation (Baek et al., 2009). Moisturizing effect of aloe vera extract can reduce inflammatory response and itching (Davis and Maro, 1989; Heggers et al., 1996). Bosse et al. (1979) reported that there was $72 \%$ improving from using Centella asiatica with surgery in scar management. After local application to a sutured wound of this herb significantly induces the breaking strength of the wound so it might reduce hardness of the scar. However, the vascularity and height scale measures were not significantly decreased in this study. It might be caused by infection, age, size and depth of burn wound. These factors alter wound healing properly and effect to produce scar. Large size and deep partial thickness burn wound always tend to form hypertrophic scar (Dunkin et al., 2007). Combination with other treatments such as steroid injection and biophysical therapy should be appropriate for these scars (Juckett and Hartman-Adams, 2009).

Our results indicated that the application of herbal extracts with a silicone derivative can gradually improved skin pliability and pigmentation as well as the concomitant symptom of scar including pain and itching.

\section{Conclusions}

Cybele ${ }^{\circledR}$ Scagel might be effective in the prevention of hypertrophic scar formation after partial-thickness burn injuries with minimal side effects. Owing to its ease of application, inexpensive treatment and benefits, Cybele ${ }^{\circledR}$ Scagel might be the adjunct in the management of scars during the wound healing process from burn injuries.

\section{REFERENCES}

Alster TS, West TB (1997). Treatment of scars: a review. Ann. Plast. Surg,, 39: 418-432.

Baek YS, Ryu YB, Curtis-Long MJ, Ha TJ, Rengasamy R, Yang MS, Park KH (2009). Tyrosinase inhibitory effects of 1,3diphenylpropanes from Broussonetia kazinoki. Bioorg. Med. Chem,, 17: 35-41.

Baryza MJ, Baryza GA (1995). The Vancouver Scar Scale: an administration tool and its interrater reliability. J. Burn. Care Rehabil,, 16: $535-538$

Beldon P (2000). Abnormal scar formation in wound healing. Nurs. Times, 96: 44-45.

Berman B, Viera MH, Amini S, Huo R, Jones IS (2008). Prevention and management of hypertrophic scars and keloids after burns in children. J. Craniofac. Surg., 19: 989-1006.

Bloemen MC, van der Veer WM, Ulrich MM, van Zuijlen PP, Niessen FB, Middelkoop E (2009). Prevention and curative management of hypertrophic scar formation. Burns, 35: 463-475.

Bock O, Schmid-Ott G, Malewski P, Mrowietz U (2006). Quality of life of patients with keloid and hypertrophic scarring. Arch. Dermatol. Res., 297: 433-438.

Bombaro KM, Engrav LH, Carrougher GJ, Wiechman SA, Faucher L, Costa BA, Heimbach DM, Rivara FP, Honari S (2003). What is the prevalence of hypertrophic scarring following burns? Burns, 29: 299302.

Bosse JP, Papillon J, Frenette G, Dansereau J, Cadotte M, Le Lorier J (1979). Clinical study of a new antikeloid agent. Ann. Plast. Surg,, 3: 13-21.

Brown JJ, Bayat A (2009). Genetic susceptibility to raised dermal scarring. Br. J. Dermatol., 161:8-18.

Chithra P, Sajithlal GB, Chandrakasan G (1998). Influence of Aloe vera on collagen characteristics in healing dermal wounds in rats. Mol. Cell. Biochem., 181: 71-76.

Davis RH, Maro NP (1989). Aloe vera and gibberellin. Anti-inflammatory activity in diabetes. J. Am. Podiatr. Med. Assoc., 79: 24-26.

Dunkin CS, Pleat JM, Gillespie PH, Tyler MP, Roberts AH, McGrouther DA (2007). Scarring occurs at a critical depth of skin injury: precise measurement in a graduated dermal scratch in human volunteers. Plast. Reconstr. Surg., 119: 1722-1732; discussion 1733-1724.

Gangemi EN, Gregori D, Berchialla P, Zingarelli E, Cairo M, Bollero D, Ganem J, Capocelli R, Cuccuru F, Cassano P, Risso D and Stella M (2008). Epidemiology and risk factors for pathologic scarring after burn wounds. Arch. Facial. Plast. Surg., 10: 93-102. 
Gauglitz GG, Korting HC, Pavicic T, Ruzicka T and Jeschke MG (2011). Hypertrophic scarring and keloids: pathomechanisms and current and emerging treatment strategies. Mol. Med., 17: 113-125.

Gold MH, Foster TD, Adair MA, Burlison K, Lewis T (2001). Prevention of hypertrophic scars and keloids by the prophylactic use of topical silicone gel sheets following a surgical procedure in an office setting. Dermatol. Surg., 27: 641-644.

Havinga R, Hartl A, Putscher J, Prehsler S, Buchmann C, Vogl C (2010). Tamarindus indica L. (Fabaceae): patterns of use in traditional African medicine. J. Ethnopharmacol., 127: 573-588.

Heggers JP, Kucukcelebi A, Listengarten D, Stabenau J, Ko F, Broemeling LD, Robson MC, WD (1996). Beneficial effect of Aloe on wound healing in an excisional wound model. J. Altern. Complement Med., 2: 271-277.

Henry G and Garner WL (2003). Inflammatory mediators in wound healing. Surg Clin North Am, 83:483-507.

Hosnuter M, Payasli C, Isikdemir A, Tekerekoglu B (2007). The effects of onion extract on hypertrophic and keloid scars. J. Wound Care, 16: 251-254.

Ju-Lin X, Shao-Hai Q, Tian-Zeng L, Bin H, Jing-Ming T, Ying-Bin X, XuSheng L, Bin S, Hui-Zhen L, Yong $H$ (2009). Effect of asiaticoside on hypertrophic scar in the rabbit ear model. J. Cutan. Pathol., 36: 234239.

Juckett G, Hartman-Adams H (2009). Management of keloids and hypertrophic scars. Am Fam Physician, 80:253-260.

Lawrence JC (1967). The effect of asiaticoside on guinea pig skin. J. Invest. Dermatol., 49: 95-96.

Muangman $P$, Chuangsuwanich $A$, Suwanchot $S$, Taengthet $O$, Benjathanung R, Chuntrasakul C (2011). Use of herbal extracts and silicone gel to prevent hypertrophic scar after burn injury: a case report. J. Assoc. Gen. Surgeons Thailand, 12: 1-8.

Muangman P, Engrav LH, Heimbach DM, Harunari N, Honari S, Gibran NS, Klein MB (2006). Complex wound management utilizing an artificial dermal matrix. Ann. Plast. Surg., 57: 199-202.

Rennekampff HO, Rabbels J, Reinhard V, Becker ST, Schaller HE (2006). Comparing the Vancouver Scar Scale with the cutometer in the assessment of donor site wounds treated with various dressings in a randomized trial. J. Burn. Care Res., 27: 345-351.

Rockwell WB, Cohen IK, Ehrlich HP (1989). Keloids and hypertrophic scars: a comprehensive review. Plast. Reconstr. Surg., 84: 827-837.
Sasaki S, Shinkai H, Akashi Y, Kishihara Y (1972). Studies on the mechanism of action of asiaticoside (Madecassol) on experimental granulation tissue and cultured fibroblasts and its clinical application in systemic scleroderma. Acta. Derm. Venereol., 52: 141-150.

Scott JR, Muangman P, Gibran NS (2007). Making sense of hypertrophic scar: a role for nerves. Wound Repair Regen, 15 Suppl. 1: S27-31.

Sherris DA, Larrabee WF, Murakami CS (1995). Management of scar contractures, hypertrophic scars, and keloids. Otolaryngol. Clin. North Am., 28: 1057-1068.

Shih B, Bayat A (2010). Genetics of keloid scarring. Arch. Dermatol. Res., 302: 319-339.

Singer AJ, McClain SA (2002). Persistent wound infection delays epidermal maturation and increases scarring in thermal burns. Wound Repair Regen., 10: 372-377.

Spencer JM (2010). Case series: evaluation of a liquid silicone gel on scar appearance following excisional surgery--a pilot study. J. Drugs Dermatol., 9: 856-858.

Stella M, Castagnoli C, Gangemi EN (2008). Postburn scars: an update. Int. J. Low Extrem. Wounds, 7: 176-181.

Tandara AA, Mustoe TA (2008). The role of the epidermis in the control of scarring: evidence for mechanism of action for silicone gel. $\mathrm{J}$. Plast. Reconstr. Aesthet. Surg., 61: 1219-1225.

van der Wal MB, van Zuijlen PP, van de Ven P, Middelkoop E (2010). Topical silicone gel versus placebo in promoting the maturation of burn scars: a randomized controlled trial. Plast. Reconstr. Surg., 126: 524-531.

Van Loey NE, Bremer M, Faber AW, Middelkoop E, Nieuwenhuis MK (2008). Itching following burns: epidemiology and predictors. Br. J. Dermatol., 158: 95-100.

Vazquez B, Avila G, Segura D, Escalante B (1996). Antiinflammatory activity of extracts from Aloe vera gel. J. Ethnopharmacol., 55: 69-75.

Widgerow AD, Chait LA, Stals R, Stals PJ (2000). New innovations in scar management. Aesthetic Plast. Surg., 24: 227-234.

Willital GH, Heine H (1994). Efficacy of Contractubex gel in the treatment of fresh scars after thoracic surgery in children and adolescents. Int. J. Clin. Pharmacol. Res., 14: 193-202.

Zurada JM, Kriegel D, Davis IC (2006). Topical treatments for hypertrophic scars. J. Am. Acad. Dermatol., 55: 1024-1031. 